\title{
Role of Protein Phosphorylation and Tyrosine Phosphatases in the Adrenal Regulation of Steroid Synthesis and Mitochondrial Function
}

\author{
Cristina Paz, Fabiana Cornejo Maciel, Alejandra Gorostizaga, Ana F. Castillo, \\ M. Mercedes Mori Sequeiros García, Paula M. Maloberti, Ulises D. Orlando, \\ Pablo G. Mele, Cecilia Poderoso and Ernesto J. Podesta*
}

\section{OPEN ACCESS}

Edited by:

Nicole Gallo-Payet,

University of Sherbrooke, Canada

Reviewed by:

Vassilios Papadopoulos,

The Research Institute of the McGill University Health Centre, Canada

Gavin P. Vinson,

Queen Mary University of London,

Jean-Jacques Feige, Institut national de la santé et de la recherche médicale, France

*Correspondence:

Ernesto J. Podesta ernestopodesta@yahoo.com.ar, biohrdc@fmed.uba.ar

Specialty section:

This article was submitted to Neuroendocrine Science,

a section of the journal

Frontiers in Endocrinology

Received: 26 February 2016 Accepted: 25 May 2016 Published: 09 June 2016

Citation:

Paz C, Cornejo Maciel F Gorostizaga A, Castillo AF, Mori Sequeiros García MM, Maloberti $P M$, Orlando UD, Mele PG, Poderoso C and Podesta EJ (2016) Role of Protein Phosphorylation and Tyrosine Phosphatases in the Adrenal Regulation of Steroid Synthesis and Mitochondrial Function. Front. Endocrinol. 7:60. doi: 10.3389/fendo.2016.00060
Departamento de Bioquímica Humana, Facultad de Medicina, Instituto de Investigaciones Biomédicas (INBIOMED), Universidad de Buenos Aires (UBA-CONICET), Ciudad Autónoma de Buenos Aires, Argentina

In adrenocortical cells, adrenocorticotropin (ACTH) promotes the activation of several protein kinases. The action of these kinases is linked to steroid production, mainly through steroidogenic acute regulatory protein (StAR), whose expression and activity are dependent on protein phosphorylation events at genomic and non-genomic levels. Hormone-dependent mitochondrial dynamics and cell proliferation are functions also associated with protein kinases. On the other hand, protein tyrosine dephosphorylation is an additional component of the ACTH signaling pathway, which involves the "classical" protein tyrosine phosphatases (PTPs), such as Src homology domain (SH) 2-containing PTP (SHP2C), and members of the MAP kinase phosphatase (MKP) family, such as MKP-1. PTPs are rapidly activated by posttranslational mechanisms and participate in hormone-stimulated steroid production. In this process, the SHP2 tyrosine phosphatase plays a crucial role in a mechanism that includes an acyl-CoA synthetase-4 (Acsl4), arachidonic acid (AA) release and StAR induction. In contrast, MKPs in steroidogenic cells have a role in the turn-off of the hormonal signal in ERK-dependent processes such as steroid synthesis and, perhaps, cell proliferation. This review analyzes the participation of these tyrosine phosphates in the ACTH signaling pathway and the action of kinases and phosphatases in the regulation of mitochondrial dynamics and steroid production. In addition, the participation of kinases and phosphatases in the signal cascade triggered by different stimuli in other steroidogenic tissues is also compared to adrenocortical cell/ $\mathrm{ACTH}$ and discussed.

Keywords: PKA, PTPs, ERK1/2, SHP2, mitochondrial dynamics, MKP-1, Acsl4 


\section{INTRODUCTION}

Steroid hormones are synthesized in steroidogenic cells of the adrenal gland, ovary, testis, placenta, and brain and are required for normal reproductive function and body homeostasis. Unlike cells producing polypeptide hormones, which store large amounts of hormone in secretory vesicles ready for rapid release, steroidogenic cells store low amounts of steroids. Thus, a rapid steroidogenic response requires a rapid synthesis of new steroid molecules.

The transport of cholesterol from the outer to the inner mitochondrial membrane (IMM) is the rate-limiting step of steroidogenesis $(1,2)$, and it is controlled by a complex mechanism that includes phosphorylation-dephosphorylation processes and the interaction of several proteins. Among these, the steroidogenic acute regulatory protein (StAR along this review, also known as STAR or more precisely STARD1) is the most widely studied $(3,4)$. Indeed, specialized reviews have focused and deeply covered the role of StAR protein in steroidogenesis $(3,4)$.

Steroid biosynthesis is finely regulated by the phosphorylation-dephosphorylation of intermediate proteins (5-9). In this regard, it is well accepted that steroidogenic hormones act through the activation of serine/threonine (Ser/Thr) protein kinases. In all steroidogenic tissues, phosphorylationdependent events are required for the acute stimulation of steroid biosynthesis through the activation of protein kinases, including cAMP-dependent protein kinase (PKA), protein kinase C (PKC), calcium/calmodulin-dependent protein kinase, and mitogenactivated protein kinases (MAPKs). Adrenocorticotropic hormone (ACTH) and luteinizing hormone (LH) [or its surrogate chorionic gonadotropin (CG)] signal transduction pathways include PKA-dependent phosphorylation events in adrenal and Leydig cells, respectively (10-12) In the adrenal zona glomerulosa, aldosterone secretion is stimulated by angiotensin II (Ang II) and $\mathrm{K}^{+}$, in addition to ACTH. These stimuli promote phosphorylation events, which are not dependent on cAMP/PKA. Indeed, $\mathrm{K}^{+}$ activates voltage-operated $\mathrm{Ca}^{2+}$ channels, while Ang II, bound to Ang II type 1 receptors, acts through the inositol 1,4,5-trisphosphate $\mathrm{IP}_{3}-\mathrm{Ca}^{2+} /$ calmodulin system (13). In other words, steroid biosynthesis is modulated by hormones, ions, or growth factors through the posttranslational phosphorylation of proteins, while the question that arises is how these phosphorylation events can lead a specific signal to its mitochondrial site of action.

Signal transduction pathways in eukaryotic cells include protein phosphorylation as an integral component regulated by the delicate balance between protein kinases and phosphatases activity. Thereby, many cellular responses require a coordinated cross talk between Ser/Thr and Tyr kinases and phosphatases activity.

In this context, this article will discuss the role of protein phosphorylation-dephosphorylation in cellular biology and endocrine function of steroidogenic cells.

\section{PROTEIN PHOSPHORYLATION}

\section{Kinases Involved in StAR Phosphorylation}

Since the middle 80s, Orme-Johnson and her group were pioneers describing the relevance of the rapid induction of a $30-\mathrm{kD}$ a protein in adrenal cortex after ACTH stimulation (14) and Leydig cells stimulated by cAMP (15). After these first discoveries, this group demonstrated that this protein is accumulated in mitochondria after hormone stimulation and processed to render two isoforms of 32 and $30 \mathrm{kDa}(16,17)$. Later, Stocco and Clark provided important data on the crucial role of this protein on the acute regulation of steroidogenesis and also on its molecular aspects. Since this protein is essential for cholesterol transport to the IMM and consequently for steroid synthesis, it was named StAR (3). Even when StAR has been widely identified as a phosphoprotein, the exact role of phosphorylation in StAR protein activity and hence cholesterol transport to the IMM still remains to be fully elucidated.

It is well established that non-genomic effects of PKA mainly involve posttranslational modifications of StAR protein. In fact, PKA phosphorylates murine and human StAR at specific residues such as Ser56/57 and Ser194/195 $(18,19)$. Moreover, genomic effects of PKA are known to include not only STAR gene (also known as STARD1 gene) transcription but also the transcriptional regulation of several steroidogenic-related genes (20). Even if cAMP-dependent signaling is the major pathway in steroid biosynthesis stimulated by ACTH and LH/CG, and PKA phosphorylation sites in StAR protein are well described, it is noteworthy that StAR sequence also contains putative phosphorylation sites for PKC, cGMP-dependent protein kinase or protein kinase $\mathrm{G}(\mathrm{PKG})$, casein kinase I and II, and cyclindependent kinase 5 (Cdk5), as it was described elsewhere for eukaryotic phosphoproteins using database Expasy Prosite $^{1}$ (21). Although the presence of these consensus sites might indicate StAR as a possible substrate for the respective kinases, the occurrence of this phosphorylation in vivo and its impact on steroid production remain uncertain.

Recent studies by Sasaki et al. - using a transgenic model with a bacterial artificial chromosome expressing either wild-type (WT) StAR or mutant StAR S194A to rescue StAR knockout mice - have demonstrated that Ser194, a conserved site among species, is an essential residue for normal StAR function in mice adrenal cortex and testis (22). These data indicate that phosphorylation of the Ser194/195 residues of StAR may account, at least in part, for the immediate increase in cholesterol side chain cleavage as a result of enhanced StAR protein activity. Consistent with these results, it has been demonstrated that the mutation in Ser195 in human mature StAR protein, which lacks the leader peptide, reduces pregnenolone production, as determined by an in vitro assay using mitochondria isolated from MA-10 Leydig cells (23). Strikingly, when cholesterol binding to StAR is measured with fluorescent or radioactive cholesterol, purified mutant S195A and WT StAR display equal binding activity. As determined by StAR structural analyses, Ser195 lies in a short loop opposite to the $\mathrm{C}-\alpha$ helix, which is essential for cholesterol binding. Therefore, the addition of phosphate-negative charge in this Ser might influence StAR activity by modifying its interaction with hypothetical mitochondrial partners such as ACBD3 (previously known as peripheral benzodiazepine receptor-associated protein, PAP7)

${ }^{1}$ http://expasy.org 
(24). This could, in turn, anchor PKA to Ser194/195, rather than alter cholesterol binding to the sterol-binding pocket (23).

In the same line, work by Stocco's group has explored the regulation mechanism of StAR expression and steroidogenesis in conjunction with PKA and PKC pathways in MA-10 Leydig cells (25). This study shows that PKC-dependent induction of steroid synthesis is low when compared to that observed with PKA signaling, but it is capable of enhance LH/CG- and/or cAMP-stimulated steroidogenic response. On the one hand, the activation of PKC markedly increases StAR expression, but not phospho-StAR, with only a modest increase in progesterone production. On the other hand, PKA activation triggers a substantial increase in the band of StAR phosphorylated in Ser194 (25).

\section{Role of ERKs in the Regulation of StAR Protein and Steroid Biosynthesis}

In addition to PKA activation importance for trophic hormonestimulated steroid biosynthesis, it is also known that extracellular signal-regulated kinases 1 and 2 (ERK1/2) and upstream activator mitogen-activated protein kinase kinase 1 and 2 (MEK1/2) participate in the regulation of steroidogenesis. Indeed, several reports describe the role of members of the MAPK family in the regulation of steroid synthesis acting at both genomic and nongenomic levels.

One of the first published works in the field indicates that cAMP-induced steroid synthesis depends on ERKs phosphorylation and activation (26). These authors show that adenylyl cyclase activation with forskolin promotes a time-dependent increase in ERK activity and translocation of this enzyme to the nucleus in mouse adrenocortical Y1 cells. Similarly, Roy et al. have demonstrated that ACTH receptor activation leads to rapid ERK1/2 phosphorylation in primary cultures of human fasciculata cells (27), an effect also observed in a human adrenocortical H295R cell line (28). Moreover, Ang II also promotes MAPK activation in adrenal glomerulosa cells $(29,30)$. Thus, ERK activation seems to be a common event in the stimulation of different steroidogenic systems.

Although already demonstrated, PKA involvement in ERK activation continues to generate controversy; Le and Shimmer have shown that ACTH increases MEK and ERK phosphorylation in Y1 adrenocortical murine cells. This effect has also been detected in Kin-8 cells, a PKA-deficient mutant Y1-derived cell line (31), which suggests that ERK activation is independent of PKA activity. H295R adrenocortical cells exhibit only a very modest cAMP response to ACTH, yet ERK1/2 response is immediate and consistent. ERK activation is minimally reduced by PKA inhibitor H89, but unaffected by PKC and calcium inhibitors. Thus, ACTH-induced ERK1/2 activation in H295R cells does not appear to depend on the mechanism by which most $G$ proteincoupled receptors activate ERK1/2, but does seem to depend on receptor internalization (28). On the other hand, Roy et al. have demonstrated the participation of PKA in ERK activation in human fasciculata cells (27).

A role for ERK activity has also been demonstrated in adrenal and gonadal steroidogenesis. Gyles et al. have shown that ERK activation results in enhanced phosphorylation of steroidogenic factor 1 (SF-1) and increased steroid production through increased transcription of the STAR gene in Y1 cells (26). The activation of the ERK/MEK pathway correlates with an increase in StAR mRNA levels, StAR protein accumulation, and steroidogenesis. Similarly, ERK inhibition leads to a reduction in the levels of forskolin-stimulated StAR mRNA, StAR protein, and steroid secretion (26).

Luteinizing hormone receptor cascade activation in Leydig cells also promotes ERK1/2 phosphorylation, which is mediated by PKA through Ras activation (32). More recently, and using mice with a Leydig-specific deletion of MEK1/2 as an experimental model, Yamashita et al. have concluded that the MEK/ ERK pathway is critical for maintaining a functional population of adult Leydig cells and fertility (33).

In agreement with findings in adrenocortical cells (26), Martinelle et al. have demonstrated the functional role of the ERK cascade in human CG (hCG)-induced steroidogenesis in primary cultures of immature rat Leydig cells (34). In this system, inhibition of MEK1/2 by U0126 suppresses several cellular responses to hCG.

In turn, 3-day treatment with Ang II in cultured rat adrenal glomerulosa cells increases aldosterone secretion through a mechanism involving both ERK1/2 and p38 MAPK pathways (30). In addition, the effect of Ang II on aldosterone synthesis also requires ERK1/2 activity in primary cultures of glomerulosa bovine cells (29).

Even though several reports support a role for ERK1/2 in StAR mRNA induction and steroid biosynthesis, other studies show controversial results. Indeed, it has been demonstrated that MEK1/2 inhibitors, such as U0126 and PD98059, enhance the expression of StAR protein in MTLC-1 and primary Leydig cells (35). Also, in MA-10 Leydig cells stimulated with dibutyryl cAMP, inhibition of ERK1/2 activity increases STAR gene expression (25). Similarly, Seger et al. have demonstrated that ERK signaling cascade inhibits CG-stimulated steroidogenesis in granulosaderived cell lines (36). Taken together, the discrepancies on the role of ERK1/2 in StAR transcription might be due to different experimental conditions and cellular types, which generate different factor availability, such as transcription factors required for StAR expression. Nevertheless, the results of Yamashita et al. strongly support the requirement of ERK for StAR expression and steroidogenesis (33). Indeed, they analyzed the role of ERK1/2 on steroidogenesis and fertility using as experimental models knockout mice carrying a deletion for MEK1/2 in Leydig cells and primary culture of Leydig cells isolated from these knockout mice. This study demonstrates that the deletion of MEK $1 / 2$ and concomitant reduction of phospho-ERK1/2 levels decreased testicular expression of several Leydig cells markers, including StAR protein. Then, a similar experimental model based on transgenic mouse should be a powerful tool to univocally demonstrate the role of ERK1/2 on ACTH action on steroidogenesis and cell growth.

Extracellular signal-regulated kinase activity seems to regulate key steroidogenic transcription factors by non-genomic and genomic actions. STAR gene transcriptional regulation requires transcription factors already present in the cell, which are activated by posttranslational modifications, such as SF1, and others which 
must be de novo synthesized, e.g., NUR77, encoded by Nr4a1 gene (37). Finally, it has been pharmacologically and molecularly demonstrated that ERK1/2 participates in cAMP-induced $\mathrm{Nr} 4 a 1$ expression in both MA-10 Leydig and Y1 adrenocortical cells (38), in addition to SF-1 activation (26).

In addition to their role in steroid biosynthesis, ERK1/2 is also involved in adrenal cell proliferation and growth (39-41). ACTH stimulates adrenal growth in vivo, whereas in vitro ACTH has an inhibitory effect on adrenal cell proliferation. In serum-starved Y1 cells, a short pulse of ACTH produces a mitogenic effect, which is preceded by the rapid activation of ERK1/2 (39). This result is in accordance with the requirement of ERK activation for cell proliferation. However, it is well documented that ACTHmediated ERK activation is a transient process in Y1 cells. Thus, the early ERK activation could trigger StAR induction, steroidogenesis, and also cell proliferation, while the following decrease in pERK levels could contribute to the inhibition of cell proliferation mediated by prolonged exposure to ACTH.

\section{ERK-Mediated Phosphorylation of StAR Protein}

The activation of the MEK1/2-ERK1/2 cascade appears to enhance steroid synthesis; nevertheless, the requirement of MEK1/2 and ERK1/2 cascade for the induction of STAR gene expression is less evident. Although it is well known the regulatory role of PKA on StAR protein activity, also this MEK1/2 and ERK1/2 cascade has been unveiled as a new mechanism of StAR activity modulation.

Our group has reported the role of MEK1/2-ERK1/2 cascade in the hCG/LH stimulation of StAR protein activity and steroidogenesis (42). In line with reports by Manna et al. and Martinelle et al. $(25,34)$, our work has shown that PKA acts upstream the stimulation of MEK and ERK activities. The inhibition of MEK1/2 on stimulated progesterone synthesis is not mediated by inhibition of PKA, as this enzyme activity is not altered in the presence of both inhibitors, U0126 and PD98095 (42).

Using a different strategy to study the role of active ERK1/2 in steroidogenesis, the overexpression of a WT form of ERK2 in MA-10 Leydig cells was performed. We observed an increase in steroid production stimulated by submaximal concentration of cAMP (42). Furthermore, an inactive form of ERK2, the H230R variant, which fails to interact with MEK1, but retains the ability to interact with MEK2 in a weakened fashion, does not produce the effect of WT ERK2 (42).

In short, both kinases, PKC and PKA, are capable of phosphorylating ERK1/2 through MEK1/2 activation $(25,32)$. ERK1/2 activity is involved in STAR gene expression induced by $\mathrm{PKC}$ or PKA activation, while a relevant role in StAR protein phosphorylation is attributed to PKA signaling pathway (25).

In summary, it is recognized that the ERK $1 / 2$ signaling cascade involved in regulating StAR expression and steroid synthesis is mediated by multiple factors and pathways, and is stimulus-specific.

\section{MEK1/2 and ERK1/2 at the Mitochondria}

The site of action of MEK inhibitors appears to be downstream of PKA activation and before of cholesterol transport, which implies that one of the targets may be located at the mitochondria. Gyles et al. have observed that activation of adenylyl cyclase causes a time-dependent increase in ERK activity and its localization from cytoplasm to nucleus (26), and our group has further proven a temporal ERK1/2 activation localized in the mitochondria, which is obligatory for PKA-mediated steroid synthesis in Leydig cells (42). Worth pointing out, the phosphorylation of mitochondrial ERK occurs before the increase in steroid production, and the hormone dose that is required for ERK activation at the mitochondria is the equivalent for eliciting steroid synthesis. Phosphorylated ERK1/2 (pERK1/2) is located in the cytosol, mitochondria, and, in lower proportion, in the nuclear fractions after cAMP stimulation. In the mitochondria and the cytosol, an early peak in ERK1/2 phosphorylation is followed by a slow progressive signal reduction during the first hour of cAMP incubation, a profile similar to that observed in hCG stimulation, leading to pERK1/2 activation. In contrast, pERK1/2 is mainly localized in the cytosol and nucleus, after epidermal growth factor (EGF) stimulation. Two different pools of MEK1/2 and pMEK1/2 have been found to be constitutively present in the cytosol and mitochondria. Remarkably, MEK1/2 differential distribution triggers different responses upon cellular stimulation (42).

Poderoso and coworkers have also shown that cAMP clearly induces sustained MEK1/2 phosphorylation in mitochondria, with a minor effect on the cytosolic kinases. Conversely, EGF induces a prolonged and strong cytosolic MEK1/2 activation, but only a discrete phosphorylation, in mitochondria. Although both EGF and cAMP increase total cytosolic MEK1/2, only EGF promotes its phosphorylation in this subcellular fraction (42).

The inhibition of PKA activity with the compound H89 and by PKA knockdown experiments diminishes the increase in mitochondrial pMEK1/2 and pERK1/2 after cAMP action (42). In agreement, the increase in mitochondrial PKA activity occurs after 5 min of cAMP action in parallel with the appearance of the phosphorylated forms of MEK1/2 and ERK1/2 in this organelle.

In regard to PKA activity and subcellular organization, a family of proteins named A-kinase anchor proteins (AKAPs) enhances cAMP-dependent pathways $(43,44)$. AKAPs raise cAMP signal by anchoring PKA near its cellular substrate, while mousederived AKAP121 binds PKA to the mitochondrial outer surface $(45,46)$. In addition, purified AKAP121 KH domain binds the 3 '-untranslated regions of transcripts encoding the Fo-f subunit of mitochondrial ATP synthase and manganese superoxide dismutase (47). A special member of the AKAP family, AKAP121, can be anchored to mitochondria and may compartmentalize PKA and other proteins on the outer mitochondria membrane (OMM) (48). In Leydig cells, cAMP-induced StAR expression and steroidogenesis were found to correlate with the extent of AKAP 121 expression (49). Expression and role of AKAP121 in H295R cells deserve elucidation. Another relevant AKAP in steroidogenic tissues is the ACBD3 protein, an acyl CoA-binding protein, known previously as PAP7 (24). Human ACBD3 is highly expressed in steroidogenic tissues, where it follows the pattern of PRKAR1A expression, suggesting that it participates in PRKAR1A-mediated tumorigenesis and hypercortisolism (50). Therefore, StAR protein is likely to be phosphorylated at the mitochondria by the activation of a cascade of kinases, including ERK. 


\section{StAR Protein as a Substrate of ERK1/2}

Steroidogenic acute regulatory protein structural analyses have revealed a consensus sequence that would allow the docking of StAR protein to ERK1/2 and a consensus site for ERK1/2 phosphorylation. A typical docking site known as the D domain (KTKLTWLLSI) lies between amino acids 235 and 244 and is conserved among MEK1/2, MAPK phosphatase, and ERK substrates (51). Regarding the ERK1/2 phosphorylation site in StAR protein, it was possible to detect only two Ser-Pro motifs, at Ser232 and Ser277, targets for ERK1/2 phosphorylation in the mature form of the murine StAR protein. In accordance with the database Expasy Prosite, ${ }^{2}$ Ser232 (PLAGS ${ }^{232} \mathrm{PS}$ ) has a $90 \%$ probability of phopshorylation and is adjacent to the docking D domain, while the probability of Ser 277 is only 5\%. Besides, Ser277 is relatively less conserved among species. In agreement of a predicted StAR-ERK binding, the treatment of subcellular fractions with pERK-GST has shown that StAR protein interacts with pERK1 just in the mitochondrial fraction, but not in the cytosol. Together, MEK phosphorylation PKA-dependent, mitochondrial StAR and pERK1/2 activity increase cholesterol transport and mitochondrial synthesis of progesterone in cell-free assays (42).

In vitro phosphorylation assays using recombinant $30-\mathrm{kDa}$ form of StAR protein and WT and the inactive mutant K71A forms of ERK1 demonstrated that the StAR protein is indeed phosphorylated by ERK1 and not by the K71A mutant. Remarkably, phosphorylation of StAR by ERK1 is dependent on the presence of cholesterol, while phosphorylation by PKA is not. Besides, StAR phosphorylation by PKA does not require previous ERK phosphorylation. By means of directed mutagenesis of Ser 232 (S232A), we demonstrated that this residue is indeed the target of ERK (42).

Expression of S232A mutated form of StAR partially blocks progesterone production enhanced by cAMP treatment in MA-10 cells. In contrast, the StAR mutant in which Ser 232 is replaced by a glutamic acid (S232E) does not produce such effect, which suggests that the negatively charged amino acid partially mimics the negative charge of the phosphate group present in the phospho-Ser (42).

Taking together, PKA phosphorylates StAR protein and also activates mitochondrial MEK1/2. Then, phosphorylated MEK1/2 activates a non-phosphorylated mitochondrial pool of ERK1/2 when the three kinases interact at the OMM, a crucial site for cholesterol transport forming a mitochondrial multi-complex with StAR.

\section{PROTEIN DEPHOSPHORYLATION}

\section{Regulation of Protein Tyrosine Phosphatases by Steroidogenic Hormones}

The degree of tyrosine phosphorylation of a given protein is the result of the action of protein tyrosine kinases and protein tyrosine phosphatases (PTPs). Protein kinases have been the focus of the research for a long time. Proportionately much less research has focused on protein phosphatases.

${ }^{2} \mathrm{http}: / /$ expasy.org/prosite/
Whereas PTPs were initially regarded as household enzymes with constitutive activity and capable of all-substrate dephosphorylation, evidence in favor of tight regulation of PTP activity by various mechanisms is now accumulating. Like protein phosphorylation, dephosphorylation by PTPs is required in a cell compartment-specific manner. Protein-protein interaction domains and compartment-specific targeting domains in PTPs serve to localize PTPs all over the cell compartments (52).

Based on the amino acid sequence of their catalytic domain, PTPs are classified into four groups, Class I, II, III (all Cysbased PTPs), and IV (Asp-based PTPs), each with a specific range of substrates. The largest family is the Class I (Cys-based PTPs), comprising the 38 "classical" PTPs, and the 61 "dualspecificity" PTPs (DSPs), which is the most diverse group in terms of substrate specificity. The group of the classical PTPs, with strict tyrosine specificity, consists of the receptor-like (transmembrane) and non-receptor (intracellular) classes. In the human genome, these PTPs comprise 21 and 17 genes, respectively $(52,53)$.

The cross talk between pathways that involve Ser/Thr phosphorylation and Tyr dephosphorylation has been described in the regulation of steroid synthesis. Our group has reported that ACTH treatment causes an increase in the activity of PTPs located in the cytosol of adrenal zona fasciculata (ZF). The stimulation is detected very soon after ACTH stimulation ( $5 \mathrm{~min}$ ), reaches a maximum (twofold) after $15 \mathrm{~min}$, and returns to basal levels after $30 \mathrm{~min}$ (54). Incubation of adrenal ZF with 8Br-cAMP (permeant analog of cAMP) also produces PTPs activation, suggesting that it can be mediated by PKA-dependent phosphorylation. Moreover, detection of PTP activity by in-gel assays has shown at least two ACTH-stimulated soluble PTPs with molecular masses of 115 and $80 \mathrm{kDa}(54)$.

Protein tyrosine phosphatases are regulated by Ser/Thr or Tyr-kinases. Indeed, several PTPs are known to be phosphoproteins in vivo $(55,56)$, which reflects the potential of crossregulation between kinases and phosphatases, either PTPs or Ser/Thr phosphatases, for the fine control of cellular activity. Among those phospho-PTPs, there is a membrane-bound form, which can be activated by treatment of intact cells with isoproterenol, forskolin, or cAMP analogs (55), and a soluble form of PTP, known as PTP-PEST, which is inhibited after in vitro phosphorylation by PKA and in HeLa cells after forskolin or methylisobutylxanthine treatment (56). Our current studies demonstrate the expression of PTP-PEST in Y1 cells and in rat adrenal ZF and suggest that the ACTH-activated PTP of $115 \mathrm{kDa}$ could be PTP-PEST. Furthermore, when paxillin is precipitated from the cytosol of ACTH-treated rats, a PTP of $115 \mathrm{kDa}$ is coprecipitated according to the analyses of precipitate by in-gel PTP assay (57).

The Src homology domain (SH) 2-containing PTP (SHP2) is classified among the non-receptor, classical PTPs. It is widely expressed and plays an essential role in many organisms from lower eukaryotes to mammals (58). In contrast to other PTPs that inactivate intracellular signaling pathways, SHP2 activates them (59). The ACTH-activated PTP of $80 \mathrm{kDa}$ from adrenal ZF has been recognized by a commercially available antibody against SHP2 in Western blot analyses (unpublished results), which 
suggests that SHP2 is a PTP activated by ACTH in rat adrenal ZF. In line with our results, Rocchi et al. have demonstrated SHP2 expression in bovine adrenocortical cells and its activation by ACTH through PKA-dependent phosphorylation (60). Finally, our group has also shown that SHP2 is expressed in MA-10 Leydig cells (61).

\section{PTP Activity and Steroidogenesis}

The rapid increase in PTP activity induced by ACTH may prove that this activity is necessary in the stimulation of steroidogenesis. Studies on PTPs role in the acute steroidogenic response to hormones have been performed using incubation of rat adrenal ZF cells with two powerful cell permeant PTP inhibitors, phenylarsine oxide (PAO) and pervanadate (PV), and evaluation of the steroid production upon stimulation by ACTH and $8 \mathrm{Br}$-cAMP. It has been proven that those PTP inhibitors block ACTH- and cAMP-stimulated corticosterone production, but exert no effects on basal steroidogenesis (54). Similar conclusions were obtained using Y1 cells $(62,63)$.

Phenylarsine oxide and PV also reduce LH/hCG- and cAMPstimulated steroid production in testicular interstitial cells (64) and in MA-10 cells (65). PTP inhibitors affect StAR induction at the protein and mRNA levels in MA-10 Leydig cells (65), as well as in Y1 cells (63). PTP inhibitors affect neither cell viability nor mitochondrial enzymatic activity evaluated as steroidogenesis triggered by 22-OH-cholesterol treatment. Thus, hormonedependent steroid synthesis requires PTP activity in a site localized beyond PKA actions and before cholesterol transport across the IMM.

Phenylarsine oxide oxidizes the thiol group of a cysteine present in the active site of all PTPs. Benzyl phosphonic acid (BPA) has a structure very similar to the PTP substrate, exerting its inhibitory action on PTPs by competitive inhibition of the enzyme. However, both inhibitors, PAO and BPA, inhibit Ang II- or $\mathrm{K}^{+}$-induced steroid synthesis in a dose-dependent fashion in H295R cells, a cell line derived from human ZG tumor (66), and in Y1 cells (63).

Collectively, our group's work demonstrates that steroidogenic stimulus (ACTH, LH, Ang II, and $\mathrm{K}^{+}$), acting by different signal transduction pathways, conveys on PTPs as common intermediaries (63-66).

In regard of substrates downstream PTP activity, in vivo ACTH treatment decreases phosphotyrosine contents in several proteins, one of them identified as paxillin, a focal adhesion protein (54). In Y1 cells, ACTH and cAMP elicit a rapid morphological transition from a flat epithelioid morphology to rounded cells (11). cAMP causes a rapid and selective Tyr dephosphorylation of paxillin in these cells (67). Moreover, the inhibition of PTP activity blocks changes in cell shape promoted by ACTH (67). Taken together, these results indicate that PTP activity is involved in cAMP-dependent paxillin dephosphorylation and this might mediate hormone-stimulated cell shape changes in adrenocortical cells.

In summary, results presented here support the view that the morphological and functional responses to ACTH in adrenocortical cells are intimately linked to and mediated by PTP activity.

\section{Links between PTP Activity and Arachidonic Acid Release}

cAMP- and PKA-dependent pathways triggered by trophic hormones in steroidogenic cells stimulate arachidonic acid (AA) release $(68,69)$. AA and its metabolites take part in the acute stimulation of steroid production. The effect is exerted on both the expression and function of StAR $(70,71)$. Previously, we proposed that free AA levels in steroidogenic cells are determined by a novel hormone-regulated mechanism $(69,72,73)$. This mechanism involves the concerted action of an acyl-CoA synthetase (Acsl4) and an acyl-CoA thioesterase (Acot2). Acsl4 is a long chain fatty acid acyl-CoA synthetase, with high affinity for $\mathrm{AA}$, and it is preferentially expressed in steroidogenic tissues (72, 74). Acot2, a thioesterase that acts on long chain fatty acyl-CoA, associates with the matrix face of mitochondrial cristae (75-77). Acot 2 mRNA and protein are present in adrenal cortex, ovary, testis, placenta, and brain, among other tissues. The activity of both enzymes is acutely modified after hormone stimulation of steroidogenic cells. Acot 2 is activated by phosphorylation and substrate availability (78), and Acsl4 is rapidly induced after hormone treatment (79).

The activity of Acsl4 and Acot2 are needed for AA release, StAR induction, and steroidogenesis. This statement is supported by the fact that the reduction of the expression of both, Acsl4 and Acot2, causes an inhibition of steroid production in two steroidogenic systems $(79,80)$. Moreover, this effect is overcome by addition of exogenous AA (80). On the basis of these results, we propose that upon hormone treatment, Acsl4 would convert free $\mathrm{AA}$ in AA-CoA. The action of mitochondrial Acot2 on AA-CoA would release AA, specifically in the mitochondria, to increase StAR and steroidogenesis (69).

Our group has also linked the sequential action of PTPs, Acsl4, and StAR to the hormone-stimulated steroid production $(66,81)$. In Y1 cells, inhibition of PTP activity prevents Acsl4 and StAR induction exerted by $8 \mathrm{Br}$-cAMP (81). Moreover, the effect of PTP inhibition is overcome by addition of exogenous AA (81). These results indicate that there is a consecutive action of PTP and Acsl4 to release AA before StAR induction. Moreover, the effect of PTPs on Acsl4 is also described in Leydig (81) and adrenocortical ZG cells (66) (Figure 1), indicating that the action of PTPs on Acsl4 may be a regulatory event that controls the steroidogenesis.

These results brought about a challenge to determine the identity of the PTP involved in the stimulation of steroid synthesis through AA release.

\section{SHP2 Involvement in Steroid Synthesis}

By means of overexpression and suppression approaches, SHP2 has been proven to be at least one of the PTPs playing an obligatory role in steroidogenesis. NSC87877, a specific inhibitor of the tyrosine phosphatase SHP2, has been shown to reduce Acsl4 protein levels in Acsl4-rich breast cancer cells and steroidogenic cells. In addition, overexpression of an active form of SHP2 has increased Acsl4 protein levels in MA-10 Leydig cells. SHP2 has to be activated through a cAMP-dependent pathway to exert its effect on Acsl4, which could be specifically attributed to SHP2, as phosphatase knockdown reduces Acsl4 


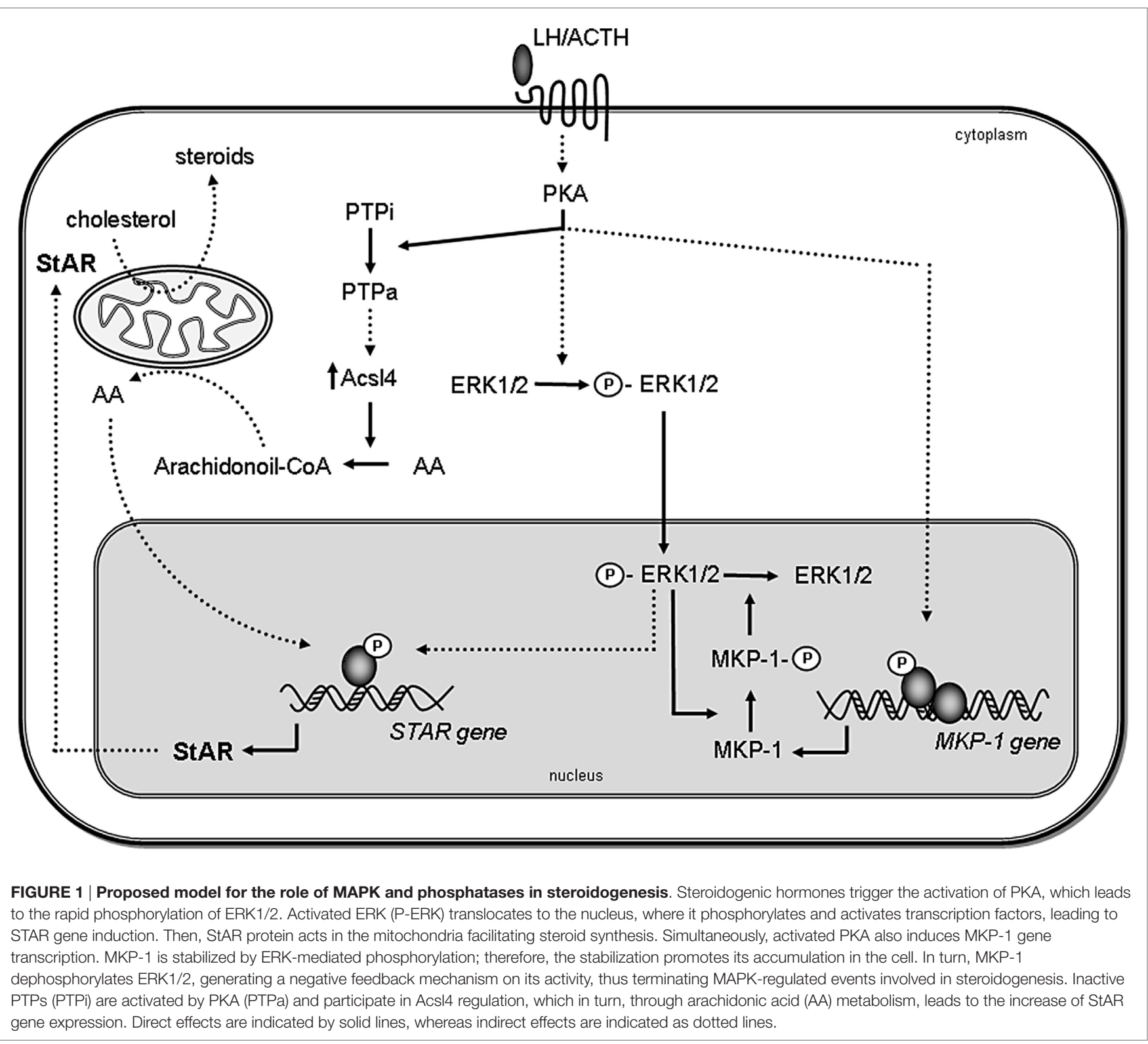

mRNA and protein levels. Through the action on Acsl4 protein levels, SHP2 affects AA-CoA production and metabolism and, finally, the steroidogenic capacity of MA-10 cells: overexpression (or knockdown) of SHP2 leads to increased (or decreased) steroid production (82).

The downregulation of SHP2 also modifies StAR expression. StAR expression increases in MA-10 Leydig cells treated with cAMP, an effect impaired by a short hairpin RNA (shRNA) against SHP2. Also, cAMP treatment causes a significant increase in StAR levels in mock-transfected cells, whereas SHP2 shRNA treatment prevents this effect. The involvement of $\mathrm{AA}$ in this process receives strong support from the fact that AA addition to SHP2 shRNA-treated cells bypasses the inhibitory effect produced by SHP2 knockdown (61). In this context, the hypothesis that arises is that a putative transcription factor, inhibited by tyrosine phosphorylation, is involved in ACTH-mediated Acsl4 induction. SHP2 could promote the tyrosine dephosphorylation of this factor, thus increasing steroid synthesis.

The Src homology domain (SH) 2-containing PTP is phosphorylated upon ACTH treatment (60). Moreover, in vitro phosphorylation of SHP2 by PKA dramatically increases its phosphatase activity (60). Although the phosphorylation of SHP2 by cAMPindependent kinases has not been demonstrated in steroidogenic cells, SHP2 may be phosphorylated by several different kinases to become Ser/Thr- or Tyr-phosphorylated. Indeed, SHP2 itself is Tyr-phosphorylated and activated through the action of different growth factors (83-86). 
The Src homology domain (SH) 2-containing PTP has been identified in mitochondria, being the first evidence of the presence of a tyrosine phosphatase in such organelle (87). Several tyrosine kinases are present in the mitochondria (88). Particularly, c-Src is involved in the modulation of the efficiency of the mitochondrial electron transport chain (88). These data become important as stimulation of steroidogenesis needs energized mitochondria, and AA export and StAR induction need the activity of complexes III and V (73). In case, SHP2 is also located in the mitochondria of steroidogenic cells, this phosphatase would be involved in the regulation of mitochondrial respiration.

The translocation of ERK to mitochondria is abolished by SHP2 knockdown in MA-10 cells. Moreover, the pronounced rearrangement of mitochondria that occurs after hCG stimulation is reduced by the downregulation of SHP2 expression (89). Then, the complete description of the steroid synthesis and secretion after hormone stimulation needs the study of SHP2 activation and mitochondrial reorganization (Figure 2).

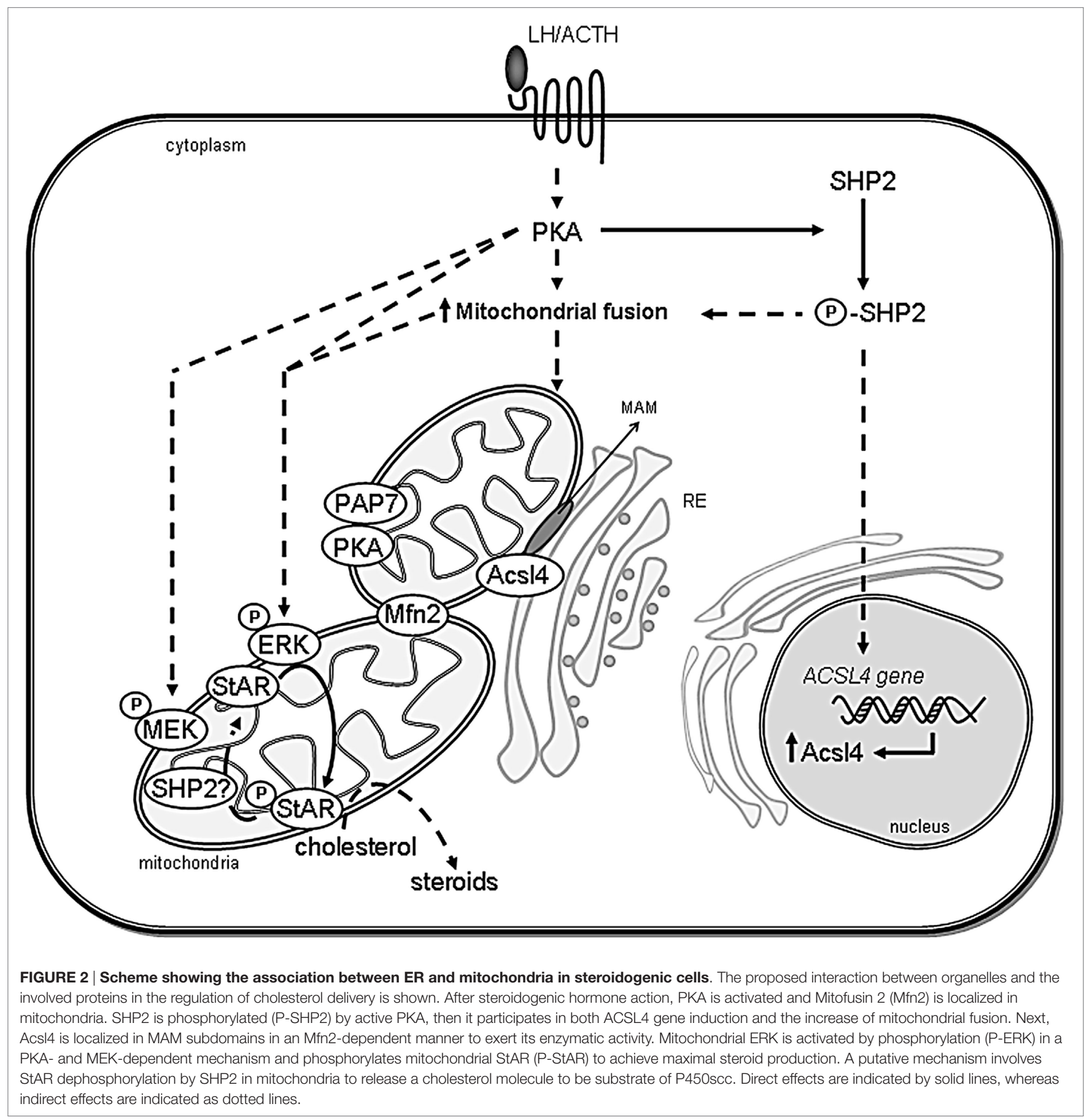




\section{MAPK Phosphatases in Steroidogenic Cells}

Given that MAPK activation depends on Thr/Tyr protein phosphorylation, the magnitude and duration of their activity are related to protein phosphatases. MAPK phosphatases (MKPs) are a family of dual activity (Thr/Tyr) protein phosphatases, which dephosphorylate specifically members of MAPKs (90, 91). Several distinct mammalian MKP family members have been identified and characterized and can be divided into two broad classes. One group, typified as MKP-1, comprises nuclear enzymes rapidly induced by growth factors or stress signals. This group also includes MKP-2, a nuclear enzyme induced by the same stimuli that induce MKP-1, but with a slower kinetics. The second group, typified as MKP-3, includes predominantly cytosolic enzymes, and their transcripts are induced with delayed kinetics by specific stimuli, but not by environmental stress.

On the basis of evidence showing that ACTH can regulate the activity of MAPKs $(31,92)$, the regulation of MKPs by this hormone is expected. Analyses on MKP-1 induction in serumstarved Y1 cells demonstrated that ACTH stimulation results in a transient increase in MKP-1 mRNA followed by an increase in protein levels (93). Sewer and Wateman have also described the regulation of MKP-1 expression by cAMP in H295R cells. In this regard, they demonstrated that MKP-1 mRNA and protein levels are induced by cAMP, and overexpression of this phosphatase stimulates hCYP17 reporter gene activity. Besides, this study also demonstrates that PKA phosphorylates MKP-1 (94).

The hormone-dependent expression of MKP-1 has also been analyzed in MA-10 Leydig cells, where hCG/cAMP rapidly increases MKP-1 gene induction in a transient manner (95). Besides, MKP-1 protein levels increased in both nuclear and mitochondrial compartments. Moreover, MKP-1 increase (95) and ERK1/2 dephosphorylation in the mitochondria (42) are temporally coordinated events. In addition, our group has demonstrated that, in cells expressing flag-MKP-1 protein, hCG/ cAMP trigger the phosphorylation and the accumulation of the recombinant protein in a time-dependent manner. Altogether, these results indicate that hCG modulates MKP-1 expression by transcriptional and posttranslational actions.

The functional role of MKP-1 in the regulation of steroidogenesis has also been analyzed in MA-10 Leydig cells. Work by our group demonstrates that MKP-1 overexpression downregulates the effects of cAMP on phospho-ERK1/2 levels, StAR expression, and steroidogenesis, while MKP-1 downregulation produces opposite effects. In summary, these data demonstrate that in Leydig cells, MKP-1 expression is regulated at multiple levels as a negative feedback regulatory mechanism to modulate the hormonal action on ERK1/2 activity and steroidogenesis (95).

Casal et al. have demonstrated the expression and regulation of MPK-1 also in primary cultures of bovine adrenal glomerulosa cells (29). These authors show that Ang II markedly increases MKP-1 protein levels in a time- and concentration-dependent manner. Ang II-induced phosphorylation of ERK1/2 leads to MKP-1 phosphorylation and, in turn, MKP-1 promotes ERK1/2 dephosphorylation. MKP-1 overexpression in bovine adrenal glomerulosa cells results in decreased phosphorylation of ERK1/2 and aldosterone production in response to Ang II stimulation. These results strongly suggest that MKP-1 is induced by Ang II and that it is involved in the negative feedback mechanism, ensuring adequate ERK1/2-mediated aldosterone production in response to the hormone.

In MA-10 Leydig cells, $\mathrm{LH}$ receptor stimulation also induces MKP-2 (96) and MKP-3 (97) through multiple mechanisms. While MKP-2 completes the ERK1/2 dephosphorylation in the nucleus initiated by MKP-1, MKP-3 dephosphorylates ERK1/2 in the cytoplasm.

In conclusion, stimuli promoting MAPK activity also regulate MKPs expression at multiple stages as a negative feedback regulatory mechanism to modulate hormonal actions on ERK1/2 activity and steroidogenesis (Figure 1).

\section{KINASES AND PHOSPHATASES IN THE REGULATION OF MITOCHONDRIAL DYNAMICS: ROLE IN STAR ACTIVITY AND STEROIDOGENESIS}

\section{StAR Structural Changes}

Several protein kinases, such as PKA, MEK, and ERK - which are essential to complete steroidogenesis - form a mitochondriaassociated complex and are completely required for mitochondrial cholesterol transport along with StAR and other proteins such as Acsl4, voltage-dependent anion channel (VDAC1), and adenine nucleotidetranslocase (ANT) $(42,98)$.

The precise mechanism of StAR action has been widely explored, but still remains elusive. StAR is synthesized as a $37-\mathrm{kDa}$ protein with a typical mitochondrial leader sequence that directs the protein to the mitochondria for the import and cleavage to an intramitochondrial form of $30-\mathrm{kDa}$ (99-102). After reaching the matrix, the $30-\mathrm{kDa}$ StAR is controlled by the ATP-dependent Lon protease (103) and proteolysed, its half-life being $4-5 \mathrm{~h}$ $(101,104)$. A tight regulation of mitochondrial StAR levels is imperative since excessive accumulation of StAR protein in the matrix provokes mitochondrial damage and a "mitochondria to nucleus" signaling which, in turn, activates transcription of genes that encode mitochondrial proteases crucial for complete clearance of StAR (105). In this regard, we have observed that the presence of mitochondrial ERK is strictly necessary for protecting StAR from unknown proteases to avoid further degradation, which constitutes one of the mechanisms playing a role in mitochondrial StAR levels regulation (106).

This mechanistic model of StAR action suggests that the active form of StAR is partially unfolded, with the N-terminal domain entering the mitochondria and the partially unfolded C-terminus interacting with the OMM. Direct evidence has been presented showing that StAR exists as a molten globule. While certain native structure is retained at the $\mathrm{N}$-terminal domain, the $\mathrm{C}$-terminal domain folding appears to be less tight at the low $\mathrm{pH}$ that StAR may undergo on the mitochondrial membrane. Then, the tightly folded N-terminal domain could make StAR halt as it enters the mitochondria, extending the time window for the C-terminus to act. 
Steroidogenic acute regulatory protein exhibits constitutive activity on the OMM, but no activity when localized to the intermembrane space (IMS) or to the matrix (107). Mitochondrial StAR protein import experiments using a modified leader peptide confirmed StAR exclusive activity on the OMM, as reflected by a negative correlation between the time of StAR mitochondrial entry and its activity. Once again, StAR role in promoting steroidogenesis is proportional to the time it spends on the OMM (107, 108).

Even when N-62 StAR form (which lacks mitochondrial peptide leader) does not access to the mitochondria, a few molecules of this protein are associated with the OMM as it is shown by immuno-electron microscopy $(108,109)$. This truncated StAR form would transport several cholesterol molecules, while complete StAR protein is able to bind just one. This suggests that StAR could transport several cholesterol molecules before entering mitochondria and be processed.

\section{Mitochondrial Dynamics and Its Regulation by Protein Kinases in Steroidogenic Cells}

"Mitochondrial dynamics," which includes fusion/fission events, is relevant for maintaining mitochondrial integrity. Indeed, mitochondrial plasticity is important for several cellular functions and for protection against aging-related changes. Among these functions, mitochondrial dynamics play a role in mitochondrial replication and repair, propagation of intramitochondrial calcium waves, and in the elimination, via mitophagy, of depolarized mitochondria (110). Two GTPases located on the OMM have a crucial role in mitochondrial fusion, mitofusin (Mfn) 1 and 2. These proteins, structurally related to dynamin, are expressed in several tissues, as brain (mainly Mfn2), liver, adrenal glands, and testis. Mfn1 and Mfn2 modulate the interactions mitochondriamitochondria and endoplasmic reticulum (ER)-mitochondria and also mediate mitochondrial fusion acting in a concerted fashion with another GTPase located in the IMM, optic atrophy 1 (OPA1).

Mitochondria have been shown to be in constant movement within the cells, and this movement can be induced after steroidogenic hormone action. This event would allow the contact between mitochondria and other membranes. It is well known that the contact between mitochondria and ER plays an important role in cell metabolism and signaling transduction pathways. Indeed, it is considered as a unique subdomain termed the mitochondria-associated ER membrane (MAM), with a vast importance in regulation of $\mathrm{Ca}^{2+}$ signaling, mitochondrial bioenergetics, apoptosis, and lipid metabolism (111-113).

Mfn2 in the ER bridges mitochondria and ER by forming homotypic and heterotypic complexes, with Mfn2 or Mfn1 on the mitochondrial surface. Therefore, Mfn2 is critical for MAM formation by tethering ER to the mitochondria. A mitochondrial ubiquitin ligase, MITOL, has been described as the regulator of the ER-mitochondria interaction by controlling Mfn2 activity (114). Interestingly, Acsl4, the key enzyme involved in the regulation of steroidogenesis through AA release and induced by steroidogenic hormones $(66,79,80)$, is localized and active in the MAM subdomain (115).

Dynamin-related protein 1 (Drp1) is required for mitochondrial fission. It is a cytosolic protein, which is recruited to the OMM by a poorly characterized multiprotein complex. In neurons, Drp1 phosphorylation by PKA in the mitochondria results in its inactivation and concomitant mitochondrial elongation (116). On the other hand, Drp1 phosphorylation by PKC 8 at Ser579 increases mitochondrial fragmentation (117). In summary, several works support a key regulatory role for phosphorylation in mitochondrial morphology maintenance.

Although it is well recognized the relevance of mitochondrial dynamics in several cellular processes, its role in steroid synthesis is poorly described. Nevertheless, a work published 30 years ago described hormone-induced changes in intracellular location of the mitochondria and in the morphology of this organelle (118). Later, it was described that mitochondria move across the cell in a PKA-dependent manner after ACTH stimulation in H295R adrenocortical cells (119). This work demonstrates that ACTH/cAMP-stimulated mitochondrial movements depend on microtubules and have a role in the regulation of cortisol production, facilitating the shuttle of steroidoigenic substrates between the ER and mitochondria (119). In this cell line, the reduction of OPA1 facilitates the transfer of cytosolic $\mathrm{Ca}^{2+}$ signal into the mitochondrial matrix (120), which results in turn in enhanced aldosterone production (121). The authors stated that this is probably due to the altered diffusion conditions under OPA1 knockout. The study of an extramitochondrial form of OPA1 closely related to the lipid droplets ruled out any role of this fraction of OPA1 in CAMP-mediated steroid hormone production, the specific biological function of adrenocortical cells $(66,120)$. Moreover, the reduction of OPA1 in Leydig cells did not affect steroid production (98), suggesting that OPA1 is not critical for hormone-induced steroidogenesis. Then, the contribution of OPA1 and cristae remodelation to steroid synthesis needs further investigation.

\section{Mitochondrial Dynamics and Steroidogenesis}

Steroid synthesis requires mitochondrial fusion induced by in a hormone-dependent fashion (89). The fact that Mfn2 is rapidly induced after the steroidogenic stimuli, and that blocking mitochondrial fusion by Mfn 2 knockdown expression reduce steroid synthesis, further supports a role of mitochondrial dynamics on steroidogenesis (89). The hormone-induced mitochondrial fusion might also be crucial for the generation of the mitochondrial multiprotein complex that facilitates the access of cholesterol to the P450scc system, since the mitochondrial rearrangement after cell stimulation is necessary for the relocalization of ERK1/2 to mitochondria. Moreover, the abrogation of mitochondrial fusion prevents the association of Acsl4 with the mitochondria, showing clearly that MAM formation depends on mitochondrial fusion (89). As previously mentioned in this review, SHP2 modulates mitochondrial fusion, suggesting that protein tyrosine dephosphorylation could be involved in the mechanism of mitochondrial dynamics (89). According to a 
published work (119), mitochondrial fusion might represent a limiting step in the onset of processes that require transport of intermediate products, e.g., liposoluble steroid hormones between organelles, probably mediated by MAM. In agreement with the previous results from our group, recent work demonstrate that hormone-induced MAM formation participates in the optimum transfer of cholesterol from the ER into the IMM increasing steroidogenesis rates (122). Then, steroid hormones might reach the plasma membrane without moving across the hydrophilic cytoplasm. Our group has shown that mitochondrial fusion is an essential process in regulating StAR mRNA levels and driving StAR to the mitochondrial context, probably participating in StAR mRNA stabilization and/or tethering the protein to the OMM (106) (Figure 2).

\section{Role of StAR Phosphorylation and Mitochondrial Fusion in StAR Localization}

In silico molecular modeling has demonstrated that cholesterol binding to StAR could elicit a conformational change in StAR C-terminal domain, which in turn might favor the exposure of StAR Ser 232 and the docking domain for ERK. Therefore, StAR could be a substrate for ERK binding and phosphorylation, only when this protein is bound to cholesterol (42). This model is sustained by the fact that cholesterol binding to StAR promotes a decrease in its helical structure (123). The OMM is the most probable environment for the interaction between StAR and ERK since this submitochondrial domain anchors both StAR and ERK, as demonstrated in the previous work $(42,53)$. In turn, the overexpression of the mutated form of StAR, S232A, in steroidogenic cells prevents StAR phosphorylation by active ERK, thus proving that the kinase indeed phosphorylates this residue.

Cholesterol acts as an allosteric modulator of its own binding to StAR (123) and is strong stabilizing of the partially unfolded state in the StAR molecule (124). However, when cholesterol has to reach the P450scc, its release from StAR hydrophobic pocket is obligatory. Since ERK phosphorylation of StAR requires cholesterol, it is conceivable to think that StAR phosphorylation at Ser232 occurs after cholesterol binding. Thus, a conformational change in StAR induced by a negative charge at the Ser232 might reduce StAR affinity for cholesterol, favoring its release. This might in turn facilitate cholesterol transport into mitochondria to achieve high rates of pregnenolone synthesis.

Steroidogenic acute regulatory protein molecular structure has been partially studied (123-126), and the Ser232 residue is predicted to be localized in one of the last $\beta$ barrels of the StAR-related lipid-transfer (START) domain $(126,127)$. It is well known that protein stability and interaction with several components are modulated by phosphorylation. Phosphorylation of proteins promotes acidic loops formation in their structure, as it has been described (128). The $\mathrm{pH}$-dependent transition to the molten globule structure in the mitochondrial context (OMM) could provoke a weakened association between StAR C-terminal $\alpha$-helix and lipid molecules, thus releasing cholesterol from StAR hydrophobic pocket. Under acidic $\mathrm{pH}$ conditions, the cholesterol affinity for START domain is significantly decreased (127). Thus, the addition of a phosphate group to StAR by ERK could establish a local decrease in $\mathrm{pH}$, directing a conformational change in StAR, to a form with a lower affinity for cholesterol.

Our group has shown that StAR S232A expression significantly diminishes the localization of StAR in the mitochondria induced by hCG or cAMP. ERK phosphorylation affects mitochondrial StAR levels posttranscriptionally, as the expression of transfected StAR S232A is independent of cellular endogenous regulation (106). The mitochondrial module includes MEK, ERK, and cholesterol with a direct physical association between StAR and ERK (42). Their interaction facilitates StAR phosphorylation by ERK. Therefore, it could lead to phospho-StAR retention in the mitochondria, particularly on the OMM where ERK resides (53) (Figure 2).

Steroidogenic acute regulatory protein activity is determined by its localization on the OMM, and not its cleavage from the $37-$ to $30-\mathrm{kDa}$ form (107). Hence, the longest StAR retention time on the OMM might render the maximal StAR activity in cholesterol transport, in agreement with the previous data (102). As described above, ERK is transiently activated after hormone stimulation in MA-10 cells (42). Its dephosphorylation could be mediated by MKP-1, since the temporal profile of mitochondrial MKP-1 and ERK dephosphorylation are compatible (95). Mitochondrial phospho-StAR and ERK interaction could avoid ERK dephosphorylation and inactivation. The temporal frame of ERK activity in this organelle correlates with highest StAR activity and cholesterol transport after hormone stimulation. These results agree with the fact that MKP-1 downregulation leads an increase in progesterone levels (95). The hormone-dependent induction of Mfn2 and mitochondrial fusion play an essential role in localization of ERK and StAR on the OMM and on the steroidogenesis $(89,129)$.

Taken together, these results offer new insights into StAR regulation by kinases and phosphatases and their impact on StAR site of action. The phosphorylation-dephosphorylation of StAR would contribute to modulate its affinity for cholesterol and to increase pregnenolone synthesis with a few molecules of StAR. In this work, we have reviewed StAR mechanism of action on cholesterol transport to the P450scc to achieve maximal steroid production. We have also described the role of phosphorylationdephosphorylation events and mitochondrial fusion as novel regulators of the localization of StAR protein in order to carry out its action in steroidogenic cells.

\section{CONCLUDING REMARKS}

Serine/threonine phosphatases have an important role in the regulation of adrenocortical cell functions, mainly steroid synthesis. In this context, the participation of PKA and PKC appears relevant, as phosphorylation events mediated by these kinases are involved in the expression and activation of StAR. Although StAR activation mechanism has not been fully described, it is known to require hormonal action on mitochondrial dynamic. Studies from other and our laboratory show that MAPKs, particularly ERK1/2, play an important role in StAR induction as 
well as in its posttranslational regulation in the mitochondria. In addition, ACTH-activated ERK1/2 regulates adrenal cell proliferation.

A field scarcely described is the role of PTPs in steroidogenic cells. We presented data on PTP activation triggered by ACTH through a PKA-dependent mechanism. In this context, PTP SHP2 has a role in the stimulation of steroidogenesis involving Acsl4 protein induction. In turn, Acsl 4 promotes AA release, StAR induction, and steroidogenesis. Moreover, SHP2 along with ERK could also have a role in steroidogenesis promoting mitochondrial fusion. MKPs, a group of dual activity phosphatases that inactivate MAPK, are also regulated by steroidogenic hormones at multiple levels. While MAPK activation is linked to steroid production activation and cell proliferation, MKP induction is associated with the turn-off of hormonal signal through MAPK inactivation and, consequently, the downregulation of ERK-dependent events.

\section{REFERENCES}

1. Crivello JF, Jefcoate CR. Intracellular movement of cholesterol in rat adrenal cells. Kinetics and effects of inhibitors. J Biol Chem (1980) 255:8144-51.

2. Privalle CT, Crivello JF, Jefcoate CR. Regulation of intramitochondrial cholesterol transfer to side-chain cleavage cytochrome P-450 in rat adrenal gland. Proc Natl Acad Sci U S A (1983) 80:702-6. doi:10.1073/pnas.80. 3.702

3. Clark BJ, Wells J, King SR, Stocco DM. The purification, cloning, and expression of a novel luteinizing hormone-induced mitochondrial protein in MA-10 mouse Leydig tumor cells. Characterization of the steroidogenic acute regulatory protein (StAR). J Biol Chem (1994) 269:28314-22.

4. Stocco DM, Clark BJ. Regulation of the acute production of steroids in steroidogenic cells. Endocr Rev (1996) 17:221-44. doi:10.1210/edrv17-3-221

5. Podesta EJ, Milani A, Steffen H, Neher R. Adrenocorticotropin (ACTH) induces phosphorylation of a cytoplasmic protein in intact isolated adrenocortical cells. Proc Natl Acad Sci U S A (1979) 76:5187-91. doi:10.1073/ pnas.76.10.5187

6. Podesta EJ, Milani A, Steffen H, Neher R. Steroidogenesis in isolated adrenocortical cells. Correlation with receptor-bound adenosine e 3':5'-cyclic monophosphate. Biochem J (1979) 180:355-63. doi:10.1042/bj1800355

7. Rae PA, Gutmann NS, Tsao J, Schimmer BP. Mutations in cyclic AMPdependent protein kinase and corticotropin (ACTH)-sensitive adenylate cyclase affect adrenal steroidogenesis. Proc Natl Acad Sci U S A (1979) 76:1896-900. doi:10.1073/pnas.76.4.1896

8. Sala GB, Hayashi K, Catt KJ, Dufau ML. Adrenocorticotropin action in isolated adrenal cells. The intermediate role of cyclic AMP in stimulation of corticosterone synthesis. J Biol Chem (1979) 254:3861-5.

9. Olson MF, Krolczyk AJ, Gorman KB, Steinberg RA, Schimmer BP. Molecular basis for the 3',5'-cyclic adenosine monophosphate resistance of Kin mutant Y1 adrenocortical tumor cells. Mol Endocrinol (1993) 7:477-87. doi:10.1210/ me.7.4.477

10. Dufau ML, Tsuruhara T, Horner KA, Podesta E, Catt KJ. Intermediate role of adenosine 3':5' -cyclic monophosphate and protein kinase during gonadotropin-induced steroidogenesis in testicular interstitial cells. Proc Natl Acad Sci U S A (1977) 74:3419-23. doi:10.1073/pnas.74.8.3419

11. Schimmer BP, Tsao J, Knapp M. Isolation of mutant adrenocortical tumor cells resistant to cyclic nucleotides. Mol Cell Endocrinol (1977) 8:135-45. doi:10.1016/0303-7207(77)90025-9

12. Podesta EJ, Dufau ML, Solano AR, Catt KJ. Hormonal activation of protein kinase in isolated Leydig cells. Electrophoretic analysis of cyclic AMP receptors. J Biol Chem (1978) 253:8994-9001.

13. Spat A, Hunyady L. Control of aldosterone secretion: a model for convergence in cellular signaling pathways. Physiol Rev (2004) 84:489-539. doi:10.1152/ physrev.00030.2003

\section{AUTHOR CONTRIBUTIONS}

Ernesto J. Podesta, Cristina Paz, Cecilia Poderoso and Ana F. Castillo wrote the paper. All authors provided critical revisions of the paper.

\section{ACKNOWLEDGMENTS}

We thank María T. Rancez for providing language help and writing assistance.

\section{FUNDING}

The authors were supported by Consejo Nacional de Investigaciones Científicas y Técnicas (CONICET), Universidad de Buenos Aires (UBA), and Agencia Nacional de Promoción Científica y Tecnológica (ANPCyT).

14. Krueger RJ, Orme-Johnson NR. Acute adrenocorticotropic hormone stimulation of adrenal corticosteroidogenesis. Discovery of a rapidly induced protein. J Biol Chem (1983) 258:10159-67.

15. Pon LA, Hartigan JA, Orme-Johnson NR. Acute ACTH regulation of adrenal corticosteroid biosynthesis. Rapid accumulation of a phosphoprotein. J Biol Chem (1986) 261:13309-16.

16. Epstein LF, Orme-Johnson NR. Regulation of steroid hormone biosynthesis. Identification of precursors of a phosphoprotein targeted to the mitochondrion in stimulated rat adrenal cortex cells. J Biol Chem (1991) 266:19739-45.

17. Epstein LF, Orme-Johnson NR. Acute action of luteinizing hormone on mouse Leydig cells: accumulation of mitochondrial phosphoproteins and stimulation of testosterone synthesis. Mol Cell Endocrinol (1991) 81:113-26. doi:10.1016/0303-7207(91)90210-J

18. Arakane F, King SR, Du Y, Kallen CB, Walsh LP, Watari H, et al. Phosphorylation of steroidogenic acute regulatory protein (StAR) modulates its steroidogenic activity. J Biol Chem (1997) 272:32656-62. doi:10.1074/ jbc. 272.51 .32656

19. Fleury A, Mathieu AP, Ducharme L, Hales DB, LeHoux JG. Phosphorylation and function of the hamster adrenal steroidogenic acute regulatory protein (StAR). J Steroid Biochem Mol Biol (2004) 91:259-71. doi:10.1016/j. jsbmb.2004.04.010

20. Tremblay JJ, Hamel F, Viger RS. Protein kinase A-dependent cooperation between GATA and CCAAT/enhancer-binding protein transcription factors regulates steroidogenic acute regulatory protein promoter activity. Endocrinology (2002) 143:3935-45. doi:10.1210/en.2002-220413

21. Blom N, Gammeltoft S, Brunak S. Sequence and structure-based prediction of eukaryotic protein phosphorylation sites. J Mol Biol (1999) 294:1351-62. doi:10.1006/jmbi.1999.3310

22. Sasaki G, Zubair M, Ishii T, Mitsui T, Hasegawa T, Auchus RJ. The contribution of serine 194 phosphorylation to steroidogenic acute regulatory protein function. Mol Endocrinol (2014) 28:1088-96. doi:10.1210/me.2014-1028

23. Baker BY, Epand RF, Epand RM, Miller WL. Cholesterol binding does not predict activity of the steroidogenic acute regulatory protein, StAR. J Biol Chem (2007) 282:10223-32. doi:10.1074/jbc.M611221200

24. Fan J, Liu J, Culty M, Papadopoulos V. Acyl-coenzyme A binding domain containing 3 (ACBD3; PAP7; GCP60): an emerging signaling molecule. Prog Lipid Res (2010) 49:218-34. doi:10.1016/j.plipres.2009.12.003

25. Manna PR, Jo Y, Stocco DM. Regulation of Leydig cell steroidogenesis by extracellular signal-regulated kinase 1/2: role of protein kinase A and protein kinase C signaling. J Endocrinol (2007) 193:53-63. doi:10.1677/ JOE-06-0201

26. Gyles SL, Burns CJ, Whitehouse BJ, Sugden D, Marsh PJ, Persaud SJ, et al. ERKs regulate cyclic AMP-induced steroid synthesis through transcription of the steroidogenic acute regulatory (StAR) gene. JBiol Chem (2001) 276:34888-95. doi:10.1074/jbc.M102063200 
27. Roy S, Pinard S, Chouinard L, Gallo-Payet N. Adrenocorticotropin hormone (ACTH) effects on MAPK phosphorylation in human fasciculata cells and in embryonic kidney 293 cells expressing human melanocortin 2 receptor (MC2R) and MC2R accessory protein (MRAP)beta. Mol Cell Endocrinol (2011) 336:31-40. doi:10.1016/j.mce.2010.12.030

28. Janes ME, Chu KM, Clark AJ, King PJ. Mechanisms of adrenocorticotropininduced activation of extracellularly regulated kinase $1 / 2$ mitogen-activated protein kinase in the human H295R adrenal cell line. Endocrinology (2008) 149:1898-905. doi:10.1210/en.2007-0949

29. Casal AJ, Ryser S, Capponi AM, Wang-Buholzer CF. Angiotensin II-induced mitogen-activated protein kinase phosphatase-1 expression in bovine adrenal glomerulosa cells: implications in mineralocorticoid biosynthesis. Endocrinology (2007) 148:5573-81. doi:10.1210/en.2007-0241

30. Otis M, Gallo-Payet N. Role of MAPKs in angiotensin II-induced steroidogenesis in rat glomerulosa cells. Mol Cell Endocrinol (2007) 26(5-266):126-30. doi:10.1016/j.mce.2006.12.008

31. Le T, Schimmer BP. The regulation of MAPKs in Y1 mouse adrenocortical tumor cells. Endocrinology (2001) 142:4282-7. doi:10.1210/endo.142.10.8441

32. Hirakawa T, Ascoli M. The lutropin/choriogonadotropin receptor-induced phosphorylation of the extracellular signal-regulated kinases in Leydig cells is mediated by a protein kinase a-dependent activation of ras. Mol Endocrinol (2003) 17:2189-200. doi:10.1210/me.2003-0205

33. Yamashita S, Tai P, Charron J, Ko C, Ascoli M. The Leydig cell MEK/ERK pathway is critical for maintaining a functional population of adult Leydig cells and for fertility. Mol Endocrinol (2011) 25:1211-22. doi:10.1210/ me.2011-0059

34. Martinelle N, Holst M, Soder O, Svechnikov K. Extracellular signal-regulated kinases are involved in the acute activation of steroidogenesis in immature rat Leydig cells by human chorionic gonadotropin. Endocrinology (2004) 145:4629-34. doi:10.1210/en.2004-0496

35. Martinat N, Crepieux P, Reiter E, Guillou F. Extracellular signal-regulated kinases (ERK) 1, 2 are required for luteinizing hormone (LH)-induced steroidogenesis in primary Leydig cells and control steroidogenic acute regulatory (StAR) expression. Reprod Nutr Dev (2005) 45:101-8. doi:10.1051/ rnd:2005007

36. Seger R, Hanoch T, Rosenberg R, Dantes A, Merz WE, Strauss JF III, et al. The ERK signaling cascade inhibits gonadotropin-stimulated steroidogenesis. J Biol Chem (2001) 276:13957-64. doi:10.1074/jbc.M006852200

37. Martin LJ, Boucher N, Brousseau C, Tremblay JJ. The orphan nuclear receptor NUR77 regulates hormone-induced StAR transcription in Leydig cells through cooperation with $\mathrm{Ca}^{2+} /$ calmodulin-dependent protein kinase I. Mol Endocrinol (2008) 22:2021-37. doi:10.1210/me.2007-0370

38. Mori Sequeiros Garcia M, Gorostizaga A, Brion L, Gonzalez-Calvar SI, Paz C. cAMP-activated Nr4al expression requires ERK activity and is modulated by MAPK phosphatase-1 in MA-10 Leydig cells. Mol Cell Endocrinol (2015) 408:45-52. doi:10.1016/j.mce.2015.01.041

39. Lotfi CF, Todorovic Z, Armelin HA, Schimmer BP. Unmasking a growthpromoting effect of the adrenocorticotropic hormone in Y1 mouse adrenocortical tumor cells. J Biol Chem (1997) 272:29886-91. doi:10.1074/jbc.272.47.29886

40. Otis M, Campbell S, Payet MD, Gallo-Payet N. Angiotensin II stimulates protein synthesis and inhibits proliferation in primary cultures of rat adrenal glomerulosa cells. Endocrinology (2005) 146:633-42. doi:10.1210/ en.2004-0935

41. Ferreira JG, Cruz CD, Neves D, Pignatelli D. Increased extracellular signal regulated kinases phosphorylation in the adrenal gland in response to chronic ACTH treatment. J Endocrinol (2007) 192:647-58. doi:10.1677/joe.1.06961

42. Poderoso C, Converso DP, Maloberti P, Duarte A, Neuman I, Galli S, et al. A mitochondrial kinase complex is essential to mediate an ERK1/2-dependent phosphorylation of a key regulatory protein in steroid biosynthesis. PLoS One (2008) 3:e1443. doi:10.1371/journal.pone.0001443

43. Rubin CS. A kinase anchor proteins and the intracellular targeting of signals carried by cyclic AMP. Biochim Biophys Acta (1994) 1224:467-79.

44. Feliciello A, Gottesman ME, Avvedimento EV. cAMP-PKA signaling to the mitochondria: protein scaffolds, mRNA and phosphatases. Cell Signal (2005) 17:279-87. doi:10.1016/j.cellsig.2004.09.009

45. Angelo RG, Rubin CS. Characterization of structural features that mediate the tethering of Caenorhabditis elegans protein kinase A to a novel A kinase anchor protein. Insights into the anchoring of PKAI isoforms. J Biol Chem (2000) 275:4351-62. doi:10.1074/jbc.275.6.4351
46. Diviani D, Scott JD. AKAP signaling complexes at the cytoskeleton. J Cell Sci (2001) 114:1431-7.

47. Ginsberg MD, Feliciello A, Jones JK, Avvedimento EV, Gottesman ME. PKAdependent binding of mRNA to the mitochondrial AKAP121 protein. J Mol Biol (2003) 327:885-97. doi:10.1016/S0022-2836(03)00173-6

48. Wong W, Scott JD. AKAP signalling complexes: focal points in space and time. Nat Rev Mol Cell Biol (2004) 5:959-70. doi:10.1038/nrm1527

49. Dyson MT, Jones JK, Kowalewski MP, Manna PR, Alonso M, Gottesman ME, et al. Mitochondrial A-kinase anchoring protein 121 binds type II protein kinase A and enhances steroidogenic acute regulatory protein-mediated steroidogenesis in MA-10 mouse leydig tumor cells. Biol Reprod (2008) 78:267-77. doi:10.1095/biolreprod.107.064238

50. Liu J, Matyakhina L, Han Z, Sandrini F, Bei T, Stratakis CA, et al. Molecular cloning, chromosomal localization of human peripheral-type benzodiazepine receptor and PKA regulatory subunit type 1A (PRKAR1A)-associated protein PAP7, and studies in PRKAR1A mutant cells and tissues. FASEB J (2003) 17:1189-91. doi:10.1096/fj.02-1066fje

51. Zhou T, Sun L, Humphreys J, Goldsmith EJ. Docking interactions induce exposure of activation loop in the MAP kinase ERK2. Structure (2006) 14:1011-9. doi:10.1016/j.str.2006.04.006

52. den Hertog J, Ostman A, Bohmer FD. Protein tyrosine phosphatases: regulatory mechanisms. FEBS $J$ (2008) 275:831-47. doi:10.1111/j.1742-4658.2008.06247.x

53. Alonso M, Melani M, Converso D, Jaitovich A, Paz C, Carreras MC, et al. Mitochondrial extracellular signal-regulated kinases $1 / 2$ (ERK1/2) are modulated during brain development. J Neurochem (2004) 89:248-56. doi:10.1111/j.1471-4159.2004.02323.x

54. Paz C, Cornejo Maciel F, Mendez C, Podesta EJ. Corticotropin increases protein tyrosine phosphatase activity by a cAMP-dependent mechanism in rat adrenal gland. Eur JBiochem (1999) 265:911-8. doi:10.1046/j.1432-1327.1999.00759.x

55. Brautigan DL, Pinault FM. Activation of membrane protein-tyrosine phosphatase involving cAMP- and $\mathrm{Ca}^{2+} /$ phospholipid-dependent protein kinases. Proc Natl Acad Sci U S A (1991) 88:6696-700. doi:10.1073/ pnas.88.15.6696

56. Garton AJ, Tonks NK. PTP-PEST: a protein tyrosine phosphatase regulated by serine phosphorylation. ЕMBO J (1994) 13:3763-71.

57. Gorostizaga AB, Mori Sequeiros Garcia MM, Acquier AB, Lopez-Costa JJ, Mendez CF, Maloberti PM, et al. ACTH modulates PTP-PEST activity and promotes its interaction with paxillin. J Cell Biochem (2016). doi:10.1002/ jcb. 25566

58. Adachi M, Iwaki H, Shindoh M, Akao Y, Hachiya T, Ikeda M, et al. Predominant expression of the src homology 2-containing tyrosine phosphatase protein SHP2 in vascular smooth muscle cells. Virchows Arch (1997) 430:321-5. doi:10.1007/BF01092755

59. Matozaki T, Murata Y, Saito Y, Okazawa H, Ohnishi H. Protein tyrosine phosphatase SHP-2: a proto-oncogene product that promotes Ras activation. Cancer Sci (2009) 100:1786-93. doi:10.1111/j.1349-7006.2009.01257.x

60. Rocchi S, Gaillard I, van Obberghen E, Chambaz EM, Vilgrain I. Adrenocorticotrophic hormone stimulates phosphotyrosine phosphatase SHP2 in bovine adrenocortical cells: phosphorylation and activation by cAMP-dependent protein kinase. Biochem J (2000) 352(Pt 2):483-90. doi:10.1042/bj3520483

61. Cooke M, Orlando U, Maloberti P, Podesta EJ, Cornejo Maciel F. Tyrosine phosphatase SHP2 regulates the expression of acyl-CoA synthetase ACSL4. J Lipid Res (2011) 52:1936-48. doi:10.1194/jlr.M015552

62. Whitehouse BJ, Gyles SL, Burns CJ, Cock MH, Jones PM. Inhibition of protein tyrosine phosphatase activity blocks shape change \& steroidogenesis in Y1 cells. Endocr Res (2000) 26:617-21. doi:10.3109/07435800009048581

63. Poderoso C, Cornejo Maciel F, Gorostizaga A, Bey P, Paz C, Podesta EJ. The obligatory action of protein tyrosine phosphatases in ACTH-stimulated steroidogenesis is exerted at the level of StAR protein. Endocr Res (2002) 28:413-7. doi:10.1081/ERC-120016816

64. Cornejo Maciel F, Poderoso C, Gorostizaga A, Paz C, Podesta EJ. LH/chorionic gonadotropin signaling pathway involves protein tyrosine phosphatase activity downstream of protein kinase A activation: evidence of an obligatory step in steroid production by Leydig cells. J Endocrinol (2001) 170:403-11. doi:10.1677/joe.0.1700403 
65. Paz C, Cornejo Maciel F, Maloberti P, Walsh LP, Stocco DM, Podesta EJ. Protein tyrosine phosphatases are involved in $\mathrm{LH} /$ chorionic gonadotropin and $8 \mathrm{Br}$-cAMP regulation of steroidogenesis and StAR protein levels in MA-10 Leydig cells. J Endocrinol (2002) 175:793-801. doi:10.1677/ joe. 0.1750793

66. Mele PG, Duarte A, Paz C, Capponi A, Podesta EJ. Role of intramitochondrial arachidonic acid and acyl-CoA synthetase 4 in angiotensin II-regulated aldosterone synthesis in NCI-H295R adrenocortical cell line. Endocrinology (2012) 153:3284-94. doi:10.1210/en.2011-2108

67. Han JD, Rubin CS. Regulation of cytoskeleton organization and paxillin dephosphorylation by cAMP. Studies on murine Y1 adrenal cells. J Biol Chem (1996) 271:29211-5. doi:10.1074/jbc.271.46.29211

68. Solano AR, Dada L, Podesta EJ. Lipoxygenase products as common intermediates in cyclic AMP-dependent and -independent adrenal steroidogenesis in rats. J Mol Endocrinol (1988) 1:147-54. doi:10.1677/jme.0.0010147

69. Castillo AF, Cornejo Maciel F, Castilla R, Duarte A, Maloberti P, Paz C, et al. cAMP increases mitochondrial cholesterol transport through the induction of arachidonic acid release inside this organelle in Leydig cells. FEBS J (2006) 273:5011-21. doi:10.1111/j.1742-4658.2006.05496.x

70. Mele PG, Dada LA, Paz C, Cymeryng CB, Cornejo Maciel MF, Neuman MI, et al. Site of action of proteinases in the activation of steroidogenesis in rat adrenal gland. Biochim Biophys Acta (1996) 1310:260-8. doi:10.1016/0167-4889(95)00177-8

71. Wang XJ, Dyson MT, Jo Y, Eubank DW, Stocco DM. Involvement of 5-lipoxygenase metabolites of arachidonic acid in cyclic AMP-stimulated steroidogenesis and steroidogenic acute regulatory protein gene expression. J Steroid Biochem Mol Biol (2003) 85:159-66. doi:10.1016/ S0960-0760(03)00189-4

72. Maloberti P, Lozano RC, Mele PG, Cano F, Colonna C, Mendez CF, et al. Concerted regulation of free arachidonic acid and hormone-induced steroid synthesis by acyl-CoA thioesterases and acyl-CoA synthetases in adrenal cells. Eur J Biochem (2002) 269:5599-607. doi:10.1046/j.1432-1033.2002.03267.x

73. Duarte A, Castillo AF, Castilla R, Maloberti P, Paz C, Podesta EJ, et al. An arachidonic acid generation/export system involved in the regulation of cholesterol transport in mitochondria of steroidogenic cells. FEBS Lett (2007) 581:4023-8. doi:10.1016/j.febslet.2007.07.040

74. Kang MJ, Fujino T, Sasano H, Minekura H, Yabuki N, Nagura H, et al. A novel arachidonate-preferring acyl-CoA synthetase is present in steroidogenic cells of the rat adrenal, ovary, and testis. Proc Natl Acad Sci U S A (1997) 94:2880-4. doi:10.1073/pnas.94.7.2880

75. Paz C, Dada LA, Cornejo Maciel MF, Mele PG, Cymeryng CB, Neuman I, et al. Purification of a novel $43-\mathrm{kDa}$ protein ( $\mathrm{p} 43$ ) intermediary in the activation of steroidogenesis from rat adrenal gland. Eur J Biochem (1994) 224:709-16. doi:10.1111/j.1432-1033.1994.00709.x

76. Finkielstein CV, Maloberti P, Mendez CF, Podesta EJ. A novel arachidonic acid-related thioesterase involved in acute steroidogenesis. Endocr Res (1998) 24:363-71. doi:10.3109/07435809809032616

77. Lindquist PJ, Svensson LT, Alexson SE. Molecular cloning of the peroxisome proliferator-induced $46-\mathrm{kDa}$ cytosolic acyl-CoA thioesterase from mouse and rat liver - recombinant expression in Escherichia coli, tissue expression, and nutritional regulation. Eur J Biochem (1998) 251:631-40. doi:10.1046/j.1432-1327.1998.2510631.x

78. Maloberti P, Mele PG, Neuman I, Cornejo Maciel F, Cano F, Bey P, et al. Regulation of arachidonic acid release in steroidogenesis: role of a new acyl-CoA thioestrase (ARTISt). Endocr Res (2000) 26:653-62. doi:10.3109/07435800009048585

79. Cornejo Maciel F, Maloberti P, Neuman I, Cano F, Castilla R, Castillo F, et al. An arachidonic acid-preferring acyl-CoA synthetase is a hormone-dependent and obligatory protein in the signal transduction pathway of steroidogenic hormones. J Mol Endocrinol (2005) 34:655-66. doi:10.1677/jme.1.01691

80. Maloberti P, Castilla R, Castillo F, Cornejo Maciel F, Mendez CF, Paz C, et al. Silencing the expression of mitochondrial acyl-CoA thioesterase I and acylCoA synthetase 4 inhibits hormone-induced steroidogenesis. FEBS J (2005) 272:1804-14. doi:10.1111/j.1742-4658.2005.04616.x

81. Cano F, Poderoso C, Cornejo Maciel F, Castilla R, Maloberti P, Castillo F, et al. Protein tyrosine phosphatases regulate arachidonic acid release, StAR induction and steroidogenesis acting on a hormone-dependent arachidonic acid-preferring acyl-CoA synthetase. J Steroid Biochem Mol Biol (2006) 99:197-202. doi:10.1016/j.jsbmb.2006.01.003

82. Cooke M, Mele P, Maloberti P, Duarte A, Poderoso C, Orlando U, et al. Tyrosine phosphatases as key regulators of StAR induction and cholesterol transport: SHP2 as a potential tyrosine phosphatase involved in steroid synthesis. Mol Cell Endocrinol (2011) 336:63-9. doi:10.1016/j.mce.2010.11.030

83. Feng GS, Hui CC, Pawson T. SH2-containing phosphotyrosine phosphatase as a target of protein-tyrosine kinases. Science (1993) 259:1607-11. doi:10.1126/ science. 8096088

84. Vogel W, Lammers R, Huang J, Ullrich A. Activation of a phosphotyrosine phosphatase by tyrosine phosphorylation. Science (1993) 259:1611-4. doi:10.1126/science.7681217

85. Bennett AM, Tang TL, Sugimoto S, Walsh CT, Neel BG. Protein-tyrosinephosphatase SHPTP2 couples platelet-derived growth factor receptor beta to Ras. Proc Natl Acad Sci U S A (1994) 91:7335-9. doi:10.1073/pnas.91.15.7335

86. Zhang EE, Chapeau E, Hagihara K, Feng GS. Neuronal Shp2 tyrosine phosphatase controls energy balance and metabolism. Proc Natl Acad Sci U S A (2004) 101:16064-9. doi:10.1073/pnas.0405041101

87. Salvi M, Stringaro A, Brunati AM, Agostinelli E, Arancia G, Clari G, et al. Tyrosine phosphatase activity in mitochondria: presence of Shp-2 phosphatase in mitochondria. Cell Mol Life Sci (2004) 61:2393-404. doi:10.1007/ s00018-004-4211-z

88. Miyazaki T, Neff L, Tanaka S, Horne WC, Baron R. Regulation of cytochrome c oxidase activity by c-Src in osteoclasts. J Cell Biol (2003) 160:709-18. doi: $10.1083 /$ jcb. 200209098

89. Duarte A, Poderoso C, Cooke M, Soria G, Cornejo Maciel F, Gottifredi V, et al. Mitochondrial fusion is essential for steroid biosynthesis. PLoS One (2012) 7:e45829. doi:10.1371/journal.pone.0045829

90. Boutros T, Chevet E, Metrakos P. Mitogen-activated protein (MAP) kinase/ MAP kinase phosphatase regulation: roles in cell growth, death, and cancer. Pharmacol Rev (2008) 60:261-310. doi:10.1124/pr.107.00106

91. Caunt CJ, Keyse SM. Dual-specificity MAP kinase phosphatases (MKPs): shaping the outcome of MAP kinase signalling. FEBS J (2013) 280:489-504. doi:10.1111/j.1742-4658.2012.08716.x

92. Watanabe G, Pena P, Albanese C, Wilsbacher LD, Young JB, Pestell RG. Adrenocorticotropin induction of stress-activated protein kinase in the adrenal cortex in vivo. JBiol Chem (1997) 272:20063-9. doi:10.1074/ jbc.272.32.20063

93. Bey P, Gorostizaga AB, Maloberti PM, Lozano RC, Poderoso C, Cornejo Maciel F, et al. Adrenocorticotropin induces mitogen-activated protein kinase phosphatase 1 in Y1 mouse adrenocortical tumor cells. Endocrinology (2003) 144:1399-406. doi:10.1210/en.2002-220987

94. Sewer MB, Waterman MR. cAMP-dependent transcription of steroidogenic genes in the human adrenal cortex requires a dual-specificity phosphatase in addition to protein kinase A. J Mol Endocrinol (2002) 29:163-74. doi:10.1677/ jme.0.0290163

95. Brion L, Maloberti PM, Gomez NV, Poderoso C, Gorostizaga AB, Mori Sequeiros Garcia MM, et al. MAPK phosphatase-1 (MKP-1) expression is up-regulated by hCG/cAMP and modulates steroidogenesis in MA-10 Leydig cells. Endocrinology (2011) 152:2665-77. doi:10.1210/en.2011-0021

96. Gomez NV, Gorostizaga AB, Mori Sequeiros Garcia MM, Brion L, Acquier A, Gonzalez-Calvar SI, et al. MAPK phosphatase-2 (MKP-2) is induced by hCG and plays a role in the regulation of CYP11A1 expression in MA-10 Leydig cells. Endocrinology (2013) 154:1488-500. doi:10.1210/ en.2012-2032

97. Mori Sequeiros Garcia M, Gomez NV, Gorostizaga A, Acquier A, GonzalezCalvar SI, Mendez CF, et al. MAP kinase phosphatase-3 (MKP-3) is transcriptionally and post-translationally up-regulated by hCG and modulates cAMP-induced p21 expression in MA-10 Leydig cells. Mol Cell Endocrinol (2013) 371:174-81. doi:10.1016/j.mce.2012.12.006

98. Rone MB, Midzak AS, Issop L, Rammouz G, Jagannathan S, Fan J, et al. Identification of a dynamic mitochondrial protein complex driving cholesterol import, trafficking, and metabolism to steroid hormones. $\mathrm{Mol}$ Endocrinol (2012) 26:1868-82. doi:10.1210/me.2012-1159

99. Jefcoate C. High-flux mitochondrial cholesterol trafficking, a specialized function of the adrenal cortex. J Clin Invest (2002) 110:881-90. doi:10.1172/ JCI0216771 
100. Allen JA, Shankara T, Janus P, Buck S, Diemer T, Hales KH, et al. Energized, polarized, and actively respiring mitochondria are required for acute Leydig cell steroidogenesis. Endocrinology (2006) 147:3924-35. doi:10.1210/ en.2005-1204

101. Granot Z, Melamed-Book N, Bahat A, Orly J. Turnover of StAR protein: roles for the proteasome and mitochondrial proteases. Mol Cell Endocrinol (2007) 265-266:51-8. doi:10.1016/j.mce.2006.12.003

102. Miller WL. Steroid hormone synthesis in mitochondria. Mol Cell Endocrinol (2013) 379:62-73. doi:10.1016/j.mce.2013.04.014

103. Granot Z, Kobiler O, Melamed-Book N, Eimerl S, Bahat A, Lu B, et al. Turnover of mitochondrial steroidogenic acute regulatory (StAR) protein by Lon protease: the unexpected effect of proteasome inhibitors. Mol Endocrinol (2007) 21:2164-77. doi:10.1210/me.2005-0458

104. Midzak A, Rone M, Aghazadeh Y, Culty M, Papadopoulos V. Mitochondrial protein import and the genesis of steroidogenic mitochondria. Mol Cell Endocrinol (2011) 336:70-9. doi:10.1016/j.mce.2010.12.007

105. Bahat A, Perlberg S, Melamed-Book N, Lauria I, Langer T, Orly J. StAR enhances transcription of genes encoding the mitochondrial proteases involved in its own degradation. Mol Endocrinol (2014) 28:208-24. doi:10.1210/me.2013-1275

106. Duarte A, Castillo AF, Podesta EJ, Poderoso C. Mitochondrial fusion and ERK activity regulate steroidogenic acute regulatory protein localization in mitochondria. PLoS One (2014) 9:e100387. doi:10.1371/journal.pone.0100387

107. Bose HS, Lingappa VR, Miller WL. The steroidogenic acute regulatory protein, StAR, works only at the outer mitochondrial membrane. Endocr Res (2002) 28:295-308. doi:10.1081/ERC-120016800

108. Arakane F, Sugawara T, Nishino H, Liu Z, Holt JA, Pain D, et al. Steroidogenic acute regulatory protein (StAR) retains activity in the absence of its mitochondrial import sequence: implications for the mechanism of StAR action. Proc Natl Acad Sci U S A (1996) 93:13731-6. doi:10.1073/pnas.93. 24.13731

109. Arakane F, Kallen CB, Watari H, Foster JA, Sepuri NB, Pain D, et al. The mechanism of action of steroidogenic acute regulatory protein (StAR). StAR acts on the outside of mitochondria to stimulate steroidogenesis. J Biol Chem (1998) 273:16339-45. doi:10.1074/jbc.273.26.16339

110. Martin SJ. Mitochondrial fusion: bax to the fussure. Dev Cell (2011) 20:142-3. doi:10.1016/j.devcel.2011.01.016

111. Rizzuto R, Brini M, Pizzo P, Murgia M, Pozzan T. Chimeric green fluorescent protein as a tool for visualizing subcellular organelles in living cells. Curr Biol (1995) 5:635-42. doi:10.1016/S0960-9822(95)00128-X

112. de Brito OM, Scorrano L. Mitofusin 2 tethers endoplasmic reticulum to mitochondria. Nature (2008) 456:605-10. doi:10.1038/nature07534

113. Vance JE. MAM (mitochondria-associated membranes) in mammalian cells: lipids and beyond. Biochim Biophys Acta (2014) 1841:595-609. doi:10.1016/j. bbalip.2013.11.014

114. Sugiura A, Nagashima S, Tokuyama T, Amo T, Matsuki Y, Ishido S, et al. MITOL regulates endoplasmic reticulum-mitochondria contacts via Mitofusin2. Mol Cell (2013) 51:20-34. doi:10.1016/j.molcel.2013.04.023

115. Lewin TM, Van Horn CG, Krisans SK, Coleman RA. Rat liver acyl-CoA synthetase 4 is a peripheral-membrane protein located in two distinct subcellular organelles, peroxisomes, and mitochondrial-associated membrane. Arch Biochem Biophys (2002) 404:263-70. doi:10.1016/S0003-9861(02)00247-3

116. Merrill RA, Dagda RK, Dickey AS, Cribbs JT, Green SH, Usachev YM, et al. Mechanism of neuroprotective mitochondrial remodeling by PKA/AKAP1. PLoS Biol (2011) 9:e1000612. doi:10.1371/journal.pbio.1000612

117. Qi X, Disatnik MH, Shen N, Sobel RA, Mochly-Rosen D. Aberrant mitochondrial fission in neurons induced by protein kinase $\mathrm{C}\{$ delta\} under oxidative stress conditions in vivo. Mol Biol Cell (2010) 22:256-65. doi:10.1091/mbc. E10-06-0551
118. Soto EA, Kliman HJ, Strauss JF III, Paavola LG. Gonadotropins and cyclic adenosine 3', ', -monophosphate (cAMP) alter the morphology of cultured human granulosa cells. Biol Reprod (1986) 34:559-69. doi:10.1095/ biolreprod34.3.559

119. LiD, Sewer MB. RhoA and DIAPH1 mediate adrenocorticotropin-stimulated cortisol biosynthesis by regulating mitochondrial trafficking. Endocrinology (2010) 151:4313-23. doi:10.1210/en.2010-0044

120. Fulop L, Szanda G, Enyedi B, Varnai P, Spat A. The effect of OPA1 on mitochondrial $\mathrm{Ca}(2)(+)$ signaling. PLoS One (2011) 6:e25199. doi:10.1371/ journal.pone.0025199

121. Spat A, Fulop L, Szanda G. The role of mitochondrial Ca(2+) and NAD(P) $\mathrm{H}$ in the control of aldosterone secretion. Cell Calcium (2012) 52:64-72. doi:10.1016/j.ceca.2012.01.009

122. Issop L, Fan J, Lee S, Rone MB, Basu K, Mui J, et al. Mitochondria-associated membrane formation in hormone-stimulated Leydig cell steroidogenesis: role of ATAD3. Endocrinology (2015) 156:334-45. doi:10.1210/ en.2014-1503

123. Petrescu AD, Gallegos AM, Okamura Y, Strauss JF III, Schroeder F. Steroidogenic acute regulatory protein binds cholesterol and modulates mitochondrial membrane sterol domain dynamics. JBiol Chem (2001) 276:36970-82. doi:10.1074/jbc.M101939200

124. Mathieu AP, Fleury A, Ducharme L, Lavigne P, LeHoux JG. Insights into steroidogenic acute regulatory protein (StAR)-dependent cholesterol transfer in mitochondria: evidence from molecular modeling and structure-based thermodynamics supporting the existence of partially unfolded states of StAR. J Mol Endocrinol (2002) 29:327-45. doi:10.1677/ jme.0.0290327

125. Tsujishita Y, Hurley JH. Structure and lipid transport mechanism of a StARrelated domain. Nat Struct Biol (2000) 7:408-14. doi:10.1038/75192

126. Yaworsky DC, Baker BY, Bose HS, Best KB, Jensen LB, Bell JD, et al. $\mathrm{pH}$-dependent Interactions of the carboxyl-terminal helix of steroidogenic acute regulatory protein with synthetic membranes. J Biol Chem (2005) 280:2045-54. doi:10.1074/jbc.M410937200

127. Reitz J, Gehrig-Burger K, Strauss JF III, Gimpl G. Cholesterol interaction with the related steroidogenic acute regulatory lipid-transfer (START) domains of StAR (STARD1) and MLN64 (STARD3). FEBS J (2008) 275:1790-802. doi:10.1111/j.1742-4658.2008.06337.x

128. Papaleo E, Ranzani V, Tripodi F, Vitriolo A, Cirulli C, Fantucci P, et al. An acidic loop and cognate phosphorylation sites define a molecular switch that modulates ubiquitin charging activity in Cdc34-like enzymes. PLoS Comput Biol (2011) 7:e1002056. doi:10.1371/journal.pcbi.1002056

129. Poderoso C, Duarte A, Cooke M, Orlando U, Gottifredi V, Solano AR, et al. The spatial and temporal regulation of the hormonal signal. Role of mitochondria in the formation of a protein complex required for the activation of cholesterol transport and steroids synthesis. Mol Cell Endocrinol (2013) 371:26-33. doi:10.1016/j.mce.2012.12.024

Conflict of Interest Statement: The authors declare that the research was conducted in the absence of any commercial or financial relationships that could be construed as a potential conflict of interest.

Copyright () 2016 Paz, Cornejo Maciel, Gorostizaga, Castillo, Mori Sequeiros García, Maloberti, Orlando, Mele, Poderoso and Podesta. This is an open-access article distributed under the terms of the Creative Commons Attribution License (CC BY). The use, distribution or reproduction in other forums is permitted, provided the original author(s) or licensor are credited and that the original publication in this journal is cited, in accordance with accepted academic practice. No use, distribution or reproduction is permitted which does not comply with these terms. 